\title{
Inteligencia artificial en todo y para todos
}

\author{
Juan Carlos Niebles
}

\begin{abstract}
Resumen
Juan Carlos Niebles es un experto en inteligencia artificial, específicamente en visión por computadora. A través de esta entrevista nos hace reflexionar sobre la importancia que la inteligencia artificial tiene en nuestras vidas en la actualidad, así como la que puede llegar a tener, en rubros como la banca, cuestiones legales, temas de salud y diagnóstico, etcétera. Asimismo, plantea que todo tipo de tecnología, no sólo la inteligencia artificial, presenta ventajas y riesgos; que en este momento este tipo de inteligencia sólo es capaz de solucionar cuestiones muy específicas y que todavía está muy lejos de la inteligencia natural para adaptarse, aprender y realizar procesos cognitivos de manera avanzada y eficiente; pero que, en general, el beneficio potencial de la inteligencia artificial para los humanos es muy elevado.
\end{abstract}

Palabras clave: inteligencia artificial, tecnología, desarrollo de tecnología, aplicaciones, riesgos.

\section{ARtificial INTELLIGENCE IN EVERYTHING AND FOR EVERYONE}

\begin{abstract}
Juan Carlos Niebles is an expert on artificial intelligence, specifically in computer vision. Through this interview, he poses the reflection on the importance of artificial intelligence in our daily lives, as well as the one that it might have in fields such as banking, legal issues, health and diagnosis, etcetera. Furthermore, he states that every type of technology, not only artificial intelligence, has advantages and risks; that at this moment such kind of intelligence is only capable of giving solution to very specific issues, and that it is still far from natural intelligence's ability of adapting, learning and doing cognitive processes in a highly advanced an efficient way, but that, in general, the potential benefit of artificial intelligent is very high to humans.
\end{abstract}

Keywords: artificial intelligence, technology, technology development, applications, risks.

Dol: http://doi.org/10.22201/codeic.16076079e.2020.v21n1.a5 


\section{Juan Carlos Niebles}

Juan Carlos Niebles es doctor en ingeniería eléctrica por Princeton y tiene cuatro responsabilidades en la universidad de Stanford: investigador científico senior en el Laboratorio de inteligencia artificial, director asociado de investigación en el Centro Toyota para investigación en inteligencia artificial, co-director del Laboratorio de visión y aprendizaje y director de currículum del programa StanfordAI4ALL. 
A partir de apenas un puñado de preguntas, Juan Carlos nos lleva por diversos caminos, retos y soluciones donde participa la inteligencia artificial (IA). La entrevista completa puede verse aquí.

\section{¿Por qué todos debemos saber de IA?}

Se trata de una tecnología que va a cambiar al mundo: basta con pensar en cómo la electricidad o internet lo hicieron. El impacto de la IA será tan grande, que es necesario que esté representado el punto de vista de todos. Esta tecnología puede ser muy poderosa, con aplicaciones para la banca, cuestiones legales y muchos otros campos.

El programa Stanford-AI4ALl tiene justamente esa intención: la idea es incrementar los puntos de vista plurales ya que actualmente no hay una representación homogénea por género y por etnicidad. En Stanford se está dando un enfoque especial a la participación de las chicas en este programa, por lo que se les invita en el décimo grado para que se puedan interesar en el tema.

\section{¿Qué beneficios y riesgos de la IA se presentan en su campo de estudio de la visión?}

La visión por computadora implica que la máquina capture imágenes, así como datos del contexto. La idea es que sea capaz de percibir el mundo. Si se tiene una cámara en un café, por ejemplo, es deseable que pueda indicar que hay dos personas en una mesa, de manera que pueda aportar asistencia en función de lo que está pasando. También es muy importante que pueda proteger la privacidad de quienes forman parte de las imágenes.

En cuanto a los riesgos, vivimos un momento temprano en el desarrollo de la IA, que resulta perfecto para conversar sobre qué es lo bueno y qué es lo malo. Sabemos que pueden ser muy útiles en cuestiones de formación, al aprender a ensamblar un aparato, por ejemplo, y que siempre está el riesgo de violar la privacidad de las personas. Esto forma parte de la conversación que debemos tener. Las ventajas y los riesgos se aplican también a tecnologías previas, como el fuego: sabemos que es una herramienta muy importante, pero también que tiene peligros potenciales.

\section{¿Cómo se compara la IA con la inteligencia natural del ser humano?}

Siempre que trabajamos con ia nos inspiramos con lo que pasa en el ser humano, en la inteligencia humana que consideramos la cosa más maravillosa de la naturaleza. El campo de la iA está todavía muy lejos de la inteligencia natural para adaptarse, aprender y hacer este tipo de procesos cognitivos de manera tan avanzada y eficiente. En este momento la ia es capaz de solucionar cuestiones muy específicas de manera muy buena. Por ejemplo, puede haber un sistema 
que juegue ajedrez y le gane incluso a campeones, pero es lo único que sabe hacer. Se trata de una inteligencia muy estrecha, muy específica.

\section{¿Hay desarrollos en las áreas de emoción y creatividad en IA?}

Resulta difícil entender qué son las emociones, cómo emergen del cerebro... Un tema ligado es el sentido común, que es algo prácticamente inexistente en la IA de hoy. En cuanto a la creatividad, es un tema muy interesante. Hemos visto, por ejemplo, algunos sistemas nuevos de ajedrez que utilizan estrategias de juego completamente diferentes a las de los jugadores humanos. Incluso los grandes maestros de ajedrez juegan con ellos y se quedan fascinados. Quizá podamos hablar de creatividad de la IA.

También existen sistemas que trabajan para industrias como la de la moda. Aquí se enfrentan al problema de saber si las creaciones que propone la IA serán del gusto de la gente. Entonces entra la colaboración entre humanos y máquinas.

\section{¿Qué reacción debemos tener ante los procesos de aprendizaje por los que pasan las IA y que no implican una supervisión humana?}

A los científicos nos intrigan los mecanismos del cerebro que permiten a los humanos aprender con pocos ejemplos y de manera no supervisada. Hoy en día las máquinas aprenden fundamentalmente de forma supervisada. Los procesos de aprendizaje no supervisado implican que absorben grandes cantidades de datos, definen patrones y comprenden los datos. Estamos aún lejos de tener técnicas que lo permitan. Si bien no hay que tener temor, sí debemos tener cuidado de que la tecnología avance por buen camino.

\section{¿Algún mensaje final para nuestros lectores?}

Sabemos que estos temas pueden despertar temores. Sin embargo, es necesario considerar que faltan décadas para que ciertos trabajos dejen de ser útiles, a partir de la automatización de procesos. Por otro lado, existen muchos beneficios de la ia en temas de salud, por ejemplo, en el área de diagnóstico, o de transporte, para que disminuyan los accidentes a partir de mayor seguridad. En general, el potencial de beneficio de la ia para los humanos es muy elevado. 


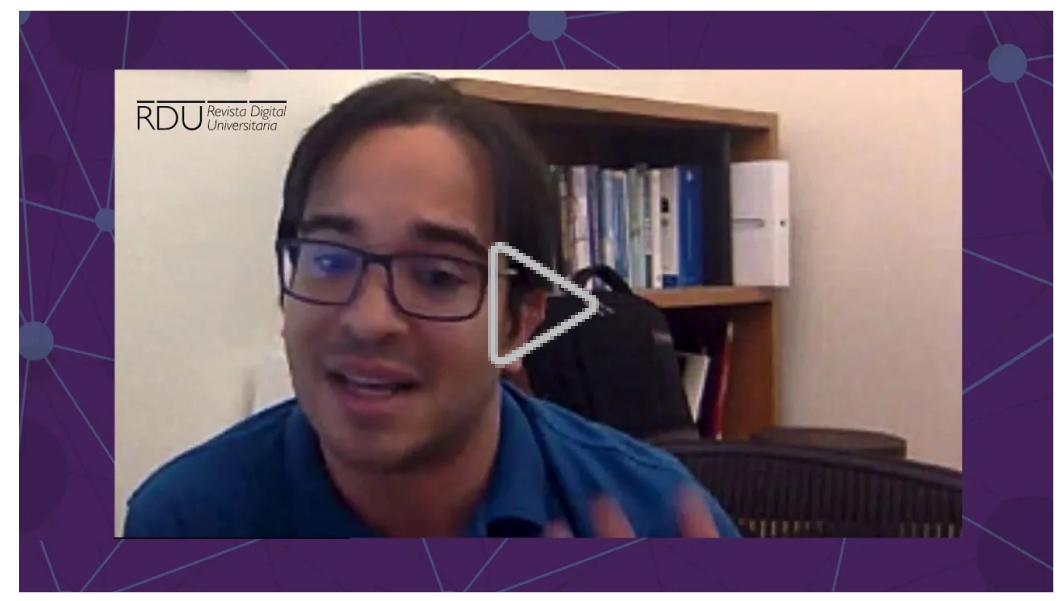

\section{Si te interesa el tema:}

Perfil de Juan Carlos Niebles en Stanford

Programa Stanford-AI4ALL

\section{Cómo citar este artículo}

* Niebles, Juan Carlos (2020). Inteligencia artificial en todo y para todos. Revista Digital Universitaria (RDU). Vol. 21, núm. 1 enero-febrero. Dol: http://doi.org/10.22201/ codeic.16076079e.2020.v21n1.a5. 